\title{
VOLTAGE DOUBLER FOR AC-DC STEP-UP LINEAR POWER SUPPLIES: DESIGN, MODELLING AND SIMULATION
}

\author{
Acácio M. R. AMARAL **** António J. M. CARDOSO** \\ *Polytechnic Institute of Coimbra, ISEC, Department of Informatics and Systems, Rua Pedro Nunes - Quinta da Nora, \\ P - 3030 - 199 Coimbra, Portugal, Tel.: +351 239790 200, Fax: +351 239790 201, E-mail: acacio@isec.pt \\ ${ }^{* *}$ CISE - Electromechatronic Systems Research Centre, Universidade da Beira Interior, Rua Marquês d'Ávila e Bolama, \\ P-6201 - 001 Covilhã, Portugal, E-mail: ajmcardoso@ieee.org
}

\begin{abstract}
This paper focuses on the design, modelling and simulation of voltage multiplier circuits for step-up AC-DC linear power supplies. The voltage multiplier is commonly used in applications that require the conversion of an AC low voltage to a very high DC voltage. Those applications require very low currents, thus, the capacitor selection is not an issue. However, when the voltage multiplier is part of a power supply, the load current becomes larger, which makes the capacitors selection more difficult. To help designers in the capacitors selection some design formulas are presented. Simultaneously, a simple simulation technique that is able to predict the circuit behaviour will be presented, revealing also essential for the design process.
\end{abstract}

Keywords: power supplies, linear regulator, voltage multiplier and capacitors

\section{INTRODUCTION}

Power supplies can be subdivided in $A C-D C$ converters, $D C-D C$ converters, $D C$ - $A C$ converters and $A C-A C$ converters.

The majority of electronic devices are powered from a $D C$ power source, so, the first two groups are the most common [1].

DC power supplies can be subdivided in linear power supplies and switched mode power supplies.

The linear power supplies are simple, durable, deliver power with low noise, have an excellent line and load regulation, a very good response time to load and line changes and low EMI [1, 2]. These power supplies contain a transformer, a rectifier, a filter and a regulator (Fig. 1).

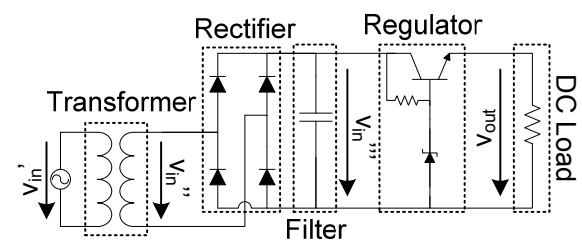

Fig. $1 A C-D C$ linear power supply

The transformer ensures electrical isolation between $A C$ primary source and the output of the power supply, and, simultaneously, step-down the voltage and step-up the current [3]. The relationship between the amplitude of the input $\left(v_{\text {in }}\right.$ ') and the output voltage $\left(v_{\text {in }}\right.$ ') $)$ of the transformer has standard values.

The bridge rectifier converts the incoming AC line voltage into a $D C$ voltage, with high harmonic content. The filter smooths the ripple of the rectified voltage, reducing the output voltage ripple and simultaneously increases the output voltage mean value. Finally, the regulator converts the unregulated $D C$ voltage ( $v_{i n}$,") into a regulated one $\left(v_{\text {out }}\right)$. The regulator holds the output voltage constant independently of the line, the DC load and the temperatures changes.

The regulator operates has a variable resistor, thus, both regulator and the $D C$ load represent a voltage divider, which means that the output voltage, $v_{\text {out }}$, is lower than $v_{i n}$ ",'. The previous analyses allow us to conclude that $v_{\text {out }}$ cannot exceed the amplitude of $v_{\text {in }}$ ", so, $v_{\text {out }}$ value is limited by the transformer turns ratio.

However, if the rectifier is replaced by a voltage multiplier, it is possible to convert the $A C$ voltage $\left(v_{i n}{ }^{\prime \prime}\right)$ into a higher $D C$ voltage $\left(v_{\text {in }}{ }^{\prime \prime}\right)$ '). Fig. 2 shows an $A C-D C$ step-up linear power supply.

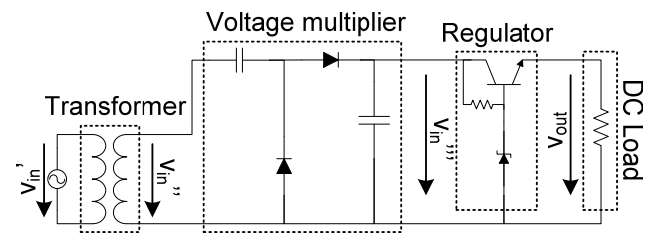

Fig. $2 A C-D C$ step-up linear power supply

The voltage multiplier converts the $A C$ electrical power from a lower voltage $\left(v_{i n}\right.$ ') $)$ to a higher $D C$ voltage $\left(v_{\text {in }}{ }^{\prime \prime}\right)$ using a network of capacitors and diodes. This circuit is commonly used in high-voltage and very low current applications typically lower than $5 \mathrm{~mA}$ [4]. The voltage multiplier is commonly used in CRT circuits [4], in high voltage pulse applications used in many industries such as plasma, ozone making, sterilization, food processing, water treatment and military applications [5, 6] and in $H V$ generators for medical $X$-ray machine [7]. In such circuits, the capacitors selection depends on the frequency of the input signal. If the voltage multiplier is used in a high frequency application $(10 \mathrm{kHz})$, the capacitors used are in the range of $20 \mathrm{nF}$ to $60 \mathrm{nF}$ [4].

However, in a linear power supply, the load current is much higher than $5 \mathrm{~mA}$, which means that the capacitors used in the voltage multiplier must be chosen appropriately. In the following sections we will address this subject.

For this purpose, in the following sections some formulas will be presented, that will prove to be very useful in the selection of the capacitors. Simultaneously, a simple simulation technique that is able to predict the 
circuit behavior will be presented. This technique reveals fundamental for the computation of some key parameters for design purposes, such as [4]:

- For the capacitors: the current rms value and the maximum voltage.

- For each rectifier: the maximum instantaneous reverse voltage, the peak forward surge current, the maximum forward current and the maximum forward voltage.

\section{VOLTAGE MULTIPLIER ANALYSIS}

The voltage multiplier under analysis, a voltage doubler, is capable of producing a $D C$ voltage that is equal to twice the amplitude of the $A C$ input voltage (Fig. 3).

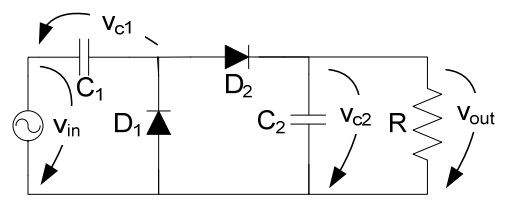

Fig. 3 Voltage doubler connected to a resistive load $(R)$

\subsection{First approximation}

In this section it will be applied the first approach, which uses the following assumptions:

- Capacitor $C_{1}$ will not discharge.

- Capacitor $C_{2}$ charges instantaneously.

- Capacitor $C_{2}$ will discharge linearly.

Using linear approach $\left(C_{2} \cdot R>>0.02\right)$, it is possible to define capacitor $C_{2}$ voltage as, $v_{C 2}(t)$ :

$v_{C 2}(t) \cong v_{C 2}(0) \cdot\left(1-\frac{t}{R \cdot C_{2}}\right)$

where: $v_{C 2}(0)$ - capacitor initial voltage, $R$ - load resistor and $C_{2}$ - capacitor capacitance.

The previous equation allows for the computation of both ripple, $\Delta v_{\text {out }}$, and mean value of the output voltage, 〈 $\left(v_{\text {out }}\right\rangle$.

$$
\left\{\begin{array}{l}
\left\langle v_{\text {out }}\right\rangle \cong v_{C 2}(0)-\frac{\Delta v_{\text {out }}}{2} \\
\Delta v_{\text {out }} \cong v_{C 2}(0) \cdot\left(\frac{1}{R \cdot C_{2} \cdot f}\right)
\end{array}\right.
$$

Since capacitor $C_{1}$ will not discharge, it is possible to write:

$$
\begin{aligned}
& v_{C 2}(0) \cong 2 \cdot V_{\text {in }}-2 \cdot V_{\gamma} \Rightarrow \\
& \Rightarrow\left\{\begin{array}{l}
\left\langle v_{\text {out }}\right\rangle \cong\left(2 \cdot V_{\text {in }}-2 \cdot V_{\gamma}\right) \cdot\left(1-\frac{1}{2 \cdot R \cdot C_{2} \cdot f}\right) \\
\Delta v_{\text {out }} \cong\left(\frac{2 \cdot V_{\text {in }}-2 \cdot V_{\gamma}}{R \cdot C_{2} \cdot f}\right)
\end{array}\right.
\end{aligned}
$$

where: $V_{\text {in }}$ - amplitude of input voltage and $V_{\gamma}$ - diode knee voltage.

\subsection{Second approximation}

In this section it will be applied the second approach, which uses the following assumptions:

- Capacitor $C_{1}$ will discharge linearly.

- Capacitor $C_{2}$ will not charge instantaneously.

- Capacitor $C_{2}$ will discharge linearly.

Although capacitor $C_{1}$ discharges, at this time, it is not possible to determine the voltage loss during the discharge period. Therefore, at this time, it will be considered that capacitor $C_{2}$ initial voltage, $v_{C 2}(0)$, is equal to:

$\left\{\begin{array}{l}V_{C 1 \text { min }} \cong V_{i n}-V_{\gamma} \\ V_{C 2}(0) \cong V_{C 1 \text { min }}+V_{\text {in }}-V_{\gamma}\end{array}\right.$

On the other hand, capacitor $C_{2}$ will not charge instantaneously, thus, it is necessary to compute the period of time that the capacitor requires to charge, $t_{\text {char }}$. For this purpose, it will be necessary to define the functions of capacitor voltage during the charging period $\left(v_{c 2 c h a r}\right)$ and during the discharging period $\left(v_{c 2 d i s c}\right)$.

$\left\{\begin{array}{l}v_{C 2 \text { ch arg }} \cong V_{C 1 \text { min }}-V_{\gamma}+V_{\text {in }} \cdot \cos (2 \cdot \pi \cdot f \cdot t-2 \cdot \pi) \\ v_{C 2 \text { disc }} \cong v_{C 2}(0) \cdot\left(1-\frac{t}{R \cdot C_{2}}\right)\end{array}\right.$

The function $v_{c 2 c h a r g}$ can be simplified using the following approximation [8]:

$\cos (x)=\sum_{k=0}^{\infty}(-1)^{k} \cdot \frac{x^{2 \times k}}{(2 \cdot k) !} \Rightarrow$
$x<<1 \Rightarrow \cos (x) \cong 1-\frac{x^{2}}{2 !} \Rightarrow$

$\left\{\begin{array}{l}v_{C 2 c h \text { arg }} \cong V_{C 1 \min }-V_{\gamma}+V_{\text {in }} \cdot\left(1-\frac{x^{2}}{2 !}\right) \\ x=2 \cdot \pi \cdot f \cdot t-2 \cdot \pi\end{array}\right.$

Therefore, by matching $v_{c 2 c h a r g}$ and $v_{c 2 d i s c}$, it is possible to compute the capacitor discharge period, $t_{\text {disc }}$, as follows:

$$
\begin{aligned}
& \left\{\begin{array}{l}
K_{1}=2 \cdot \pi^{2} \cdot f^{2} \cdot V_{\text {in }} \\
K_{2}=-\frac{V_{C 1 \text { min }}+V_{\text {in }}-V_{\gamma}}{R \cdot C_{2}}-4 \cdot \pi^{2} \cdot f \cdot V_{i n} \\
K_{3}=2 \cdot \pi^{2} \cdot V_{i n}
\end{array}\right. \\
& t_{\text {disc }} \cong \frac{-K_{2}-\sqrt{K_{2}^{2}-4 \cdot K_{1} \cdot K_{3}}}{2 \cdot K_{1}}
\end{aligned}
$$

The time-period that $C_{2}$ takes to charge, $t_{\text {char }}$, is equal to:

$t_{\text {char }} \cong \frac{1}{f}-t_{\text {disc }}$

In this way, using a linear approach, it is possible to compute the output voltage ripple as: 
$\Delta v_{\text {out }} \cong \frac{v_{C 2}(0) \cdot t_{\text {disc }}}{R \cdot C_{2}}$

To compute the mean value of the output voltage it is necessary to know the voltage loss in $C_{1}$ during the discharging period. For that, it is necessary to compute the capacitor $C_{1}$ current during the discharging period, $i_{C 1 d i s c}$.

$$
\begin{aligned}
& i_{\text {C1disc }} \cong \frac{\left\langle v_{C 2 \text { charg }}\right\rangle}{R}+i_{C 2 \text { charg }} \\
& i_{C 1 \text { disc }} \cong \frac{v_{C 2}(0)-\frac{\Delta v_{\text {out }}}{2}}{R}+C_{2} \cdot \frac{\Delta v_{\text {out }}}{t_{\text {char }}} \Rightarrow \\
& i_{C 1 \text { disc }} \cong \frac{\left(V_{C 1 \text { min }}+V_{\text {in }}-V_{\gamma}\right)-\frac{\Delta v_{\text {out }}}{2}}{R}+C_{2} \cdot \frac{\Delta v_{\text {out }}}{f^{-1}-t_{\text {disc }}}
\end{aligned}
$$

where: $V_{C 1 \text { min }}$ - the minimum value of capacitor $C_{1}$ voltage during steady-state regime, $\left\langle v_{C 2 \text { charg }}\right\rangle$ - the mean value of capacitor $C_{2}$ voltage during the charging period in steadystate regime and $i_{C 2 \text { charg }}$ - capacitor $C_{2}$ current during the charging period in steady-state regime.

It is important to notice that capacitor $C_{1}$ discharges when capacitor $C_{2}$ charges. Thus, it is possible to compute capacitor $C_{1}$ ripple voltage as, $\Delta v_{c 1}$ :

$\Delta v_{C 1} \cong \frac{i_{\text {Cldisc }} \cdot\left(f^{-1}-t_{\text {disc }}\right)}{C_{1}}$

The previous value represents the voltage loss in $C_{1}$ during the discharging period. Thus, it is possible to compute the output mean value, $\left\langle\mathrm{v}_{\text {out }}\right\rangle$, as well as the new value of $V_{c 1 \text { min }}$ :

$$
\begin{aligned}
& V_{C 1 \text { min }}=V_{\text {in }}-V_{\gamma}-\Delta v_{C 1} \\
& v_{C 2}(0)=V_{C 1 \text { min }}+V_{\text {in }}-V_{\gamma}=2 \cdot V_{\text {in }}-2 \cdot V_{\gamma}-\Delta v_{C 1} \\
& \left\langle v_{\text {out }}\right\rangle \cong v_{C 2}(0) \cdot\left(1-\frac{t_{\text {disc }}}{2 \cdot R \cdot C_{2}}\right)
\end{aligned}
$$

At this point, it is possible to compute the output voltage ripple more accurately.

$\Delta v_{\text {out }} \cong \frac{v_{C 2}(0) \cdot t_{\text {disc }}}{R \cdot C_{2}}$

\section{VOLTAGE DOUBLER DESIGN}

Section 2.2 allows us to obtain a set of formulas that can be used in the design of a voltage doubler.

In the design of this circuit two basic specifications will be considered: the average value of the output voltage, $\left\langle v_{\text {out }}\right\rangle$, and its voltage ripple, $\Delta v_{\text {out }}$.

Initially, the value of the capacity of $C_{2}$ will be computed, because this value will affect the selection of capacitor $C_{1}$, and for that equation (3) can be used.
$C_{2} \geq\left(\frac{2 \cdot V_{\text {in }}-2 \cdot V_{\gamma}}{R \cdot \Delta v_{\text {out }} \cdot f}\right)$

The above formula is oversized, since, $v_{C 2}(0)$ is greater than a real one and the discharging period is maximum.

Afterwards, it will be possible to compute $C_{1}$ minimum value using equations (10) and (11).

$$
\left\{\begin{array}{l}
t_{\text {disc }} \cong \frac{-K_{2}-\sqrt{K_{2}^{2}-4 \cdot K_{1} \cdot K_{3}}}{2 \cdot K_{1}} \rightarrow \operatorname{see}(7) \\
\Delta v_{\text {out }} \geq\left(\frac{2 \cdot V_{\text {in }}-2 \cdot V_{\gamma}}{R \cdot C_{2} \cdot f}\right) \\
\Delta v_{C 1}=2 \cdot V_{\text {in }}-2 \cdot V_{\gamma}-\left\langle v_{\text {out }}\right\rangle-\frac{\Delta v_{\text {out }}}{2} \\
i_{\text {C1disc }} \cong \frac{v_{C 2}(0)-\frac{\Delta v_{\text {out }}}{2}}{R}+C_{2} \cdot \frac{\Delta v_{\text {out }}}{f^{-1}-t_{\text {disc }}} \\
C_{1} \geq \frac{i_{\text {cldisc }} \cdot\left(f^{-1}-t_{\text {disc }}\right)}{\Delta v_{C 1}}
\end{array}\right.
$$

The capacitances obtained from the previous formulas should be oversized. Afterwards, it will be presented an algorithm that improves the selection of capacitors capacitance.

\subsection{Algorithm for more accurate design}

The following algorithm allows for the selection of smaller capacitance capacitors and simultaneously respecting the original specifications.

In order to understand the algorithm it is important to provide some definitions.

- MAX_ERROR_ripple - is the largest permissible difference between the computed value and the specified output voltage ripple.

- MAX_ERROR_mean - is the largest permissible difference between the computed value and the specified mean value of the output voltage.

- CALC_ripple - is the computed value of the output voltage ripple.

- SPEC_ripple - is the specified value of the output voltage ripple.

- CALC_mean - is the computed mean value of the output voltage.

- $\quad$ SPEC_mean - is the specified mean value of the output voltage.

- $\quad$ ERROR_ripple $=$ CALC_ripple $-\mathrm{SPEC}$ _ripple.

- ERROR_mean $=$ CALC_mean - SPEC_mean.

- $\quad$ INC_C1 - increment/decrement of $C_{1}$ capacitance.

- INC_C2 - increment/decrement of $C_{2}$ capacitance.

- $\mathrm{I}_{\mathrm{Cldesc}}$ - capacitor $C_{1}$ current during $C_{1}$ discharge period. 
Before using the previous algorithm it is necessary to compute the first iteration, which provides the initial capacitance of both capacitors $\left(C_{10}\right.$ and $\left.C_{20}\right)$, and for that, equations (14) and (15) should be used. Using the previous values together with (11) it is possible to compute capacitor $C_{1}$ voltage ripple $\left(\Delta V_{C 1}\right)$.

Afterwards, the algorithm will be presented.

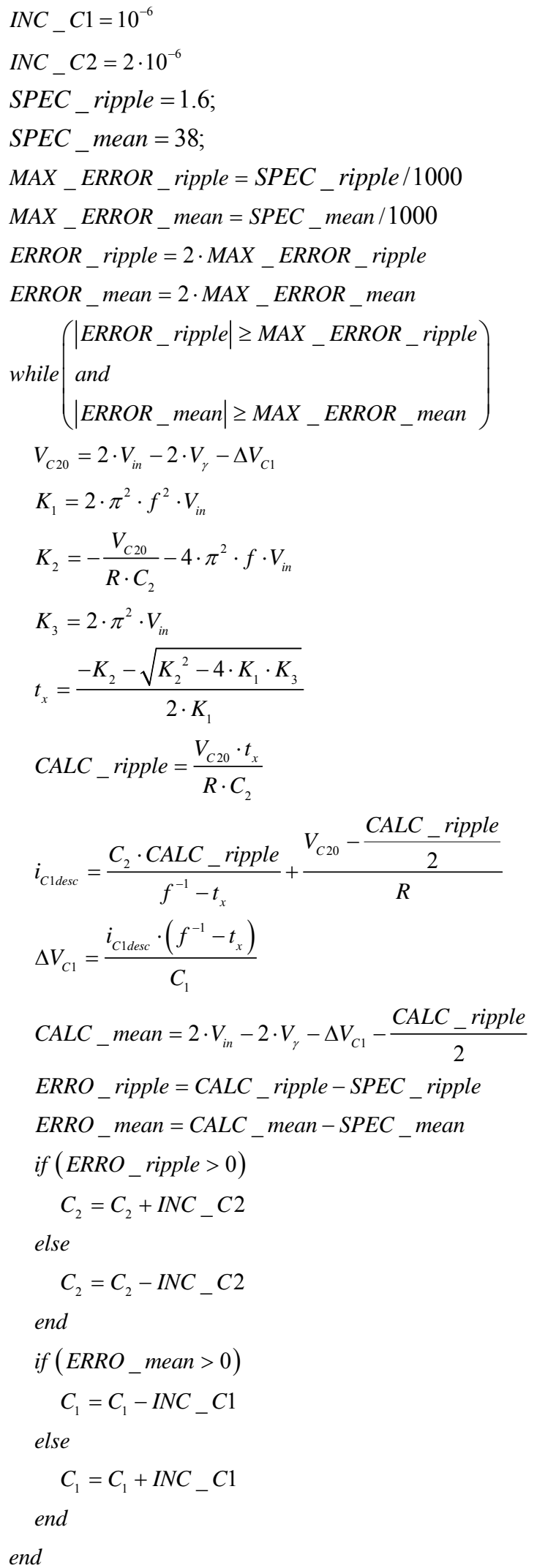

\section{VOLTAGE DOUBLER SIMULATION}

In this section a simple simulation technique will be presented, which has the following steps:

1. Draw the whole circuit and its components.

2. Identify all the states.

3. Recognize the conditions that satisfy the occurrence of each state.

4. Analyze each state, and get the mathematical equations that describe its operation.

5. Represent the sequence of states in the form of an algorithm.

Fig. 3 shows the circuit under analysis (voltage doubler), which has three different states:

- $\quad$ State 1 - Diode $D_{1}$ conducts and Diode $D_{2}$ do not conduct.

- $\quad$ State 2 - Diode $D_{2}$ conducts and Diode $D_{1}$ do not conduct.

- $\quad$ State 3 - None of the diodes conducts.

Afterwards, the conditions that determine the occurrence of each state, are presented:

- The first state occurs when:

$$
\mathrm{v}_{\text {in }}+\mathrm{v}_{\mathrm{C} 1} \leq-\mathrm{v}_{\gamma} \text { and } \mathrm{v}_{\text {in }}+\mathrm{v}_{\mathrm{C} 1}-\mathrm{v}_{\mathrm{C} 2}<\mathrm{V}_{\gamma}
$$

- The second state occurs when:

$$
\mathrm{v}_{\text {in }}+\mathrm{v}_{\mathrm{C} 1}>-\mathrm{V}_{\gamma} \text { and } \mathrm{v}_{\text {in }}+\mathrm{v}_{\mathrm{C} 1}-\mathrm{v}_{\mathrm{C} 2} \geq \mathrm{V}_{\gamma}
$$

- The third state occurs when:

$$
\mathrm{v}_{\text {in }}+\mathrm{v}_{\mathrm{C} 1}>-\mathrm{V}_{\gamma} \text { and } \mathrm{v}_{\text {in }}+\mathrm{v}_{\mathrm{C} 1}-\mathrm{v}_{\mathrm{C} 2}<\mathrm{v}_{\gamma}
$$

Subsequently, each state will be analyzed.

\subsection{State Analysis}

Fig. 4 shows the equivalent circuit corresponding to the first state.
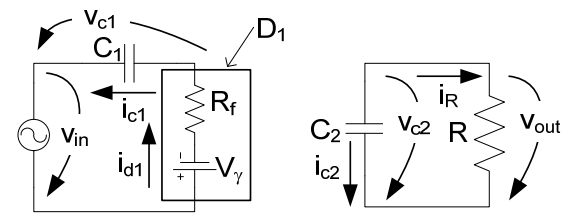

Fig. 4 Equivalent circuit corresponding to the first state

It is convenient to represent the diode $\left(D_{1}\right)$ by its largesignal model, (diode model when forward bias $-\left[R_{f}+\right.$ $\left.V_{\gamma}\right]$ ), in order to evaluate the currents and voltages in the network using standard analysis methods [9].

From the analysis of the previous circuit it is possible to write the resulting equations:

$$
\left\{\begin{array}{l}
v_{i n}+v_{c 1}+V_{\gamma}+R_{f} \cdot i_{d}=0 \\
i_{d}=i_{c 1}=C_{1} \cdot \frac{d v_{c 1}}{d t} \\
i_{c 2}=-i_{R}=-\frac{v_{c 2}}{R}=C_{2} \cdot \frac{d v_{c 2}}{d t}
\end{array}\right.
$$

Fig. 5 shows the equivalent circuit corresponding to the second state. 


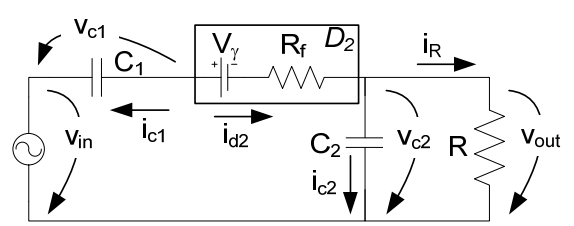

Fig. 5 Equivalent circuit corresponding to the second state

From the analysis of the previous circuit it is possible to write the following equations:

$$
\left\{\begin{array}{l}
v_{i n}-v_{c 1}+V_{\gamma}+R_{f} \cdot\left(-i_{c 1}\right)+v_{c 2}=0 \\
i_{c 1}=-i_{c 2}-\frac{v_{c 2}}{R} \\
i_{c 2}=C_{2} \cdot \frac{d v_{c 2}}{d t} \\
i_{c 1}=C_{1} \cdot \frac{d v_{c 1}}{d t}
\end{array}\right.
$$

Fig. 6 shows the equivalent circuit corresponding to the third state.

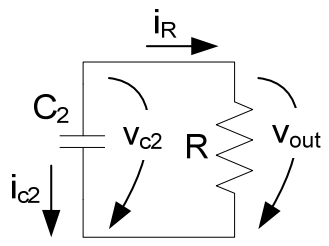

Fig. 6 Equivalent circuit corresponding to the third state

From the analysis of the previous circuit it is possible to write the following equation:

$i_{c 2}=-i_{R}=-\frac{v_{c 2}}{R}=C_{2} \cdot \frac{d v_{c 2}}{d t}$

\subsection{Algorithm}

Finally, representing the above equations, (16)-(18), in their discrete form, it is possible to develop a simulation program, which can be easily implemented in an opensource platform for numerical computation. $\mathrm{i}=1$

Following, a small algorithm is presented:

$$
\begin{aligned}
& \text { while }(\mathrm{i}<\mathrm{NTP}) \\
& \text { if }\left(\left(v_{\text {in }}(i)+v_{c 1}(i) \leq-v_{y}\right) \text { and }\left(v_{\text {in }}(i)+v_{c 1}(i)-v_{c 2}(i)<v_{y}\right)\right) \\
& \mathrm{K}_{1}=\mathrm{R}_{\mathrm{f}} \cdot \mathrm{C}_{1} \quad ; \quad \mathrm{K}_{2}=\mathrm{R} \cdot \mathrm{C}_{2} \\
& \mathrm{v}_{\mathrm{cl}}(\mathrm{i}+1)=\frac{\mathrm{PA}}{\mathrm{K}_{1}} \cdot\left(\mathrm{v}_{\mathrm{in}}(\mathrm{i})+\mathrm{V}_{\gamma}\right)+\left(1-\frac{\mathrm{PA}}{\mathrm{K}_{1}}\right) \cdot \mathrm{v}_{\mathrm{cl}}(\mathrm{i}) \\
& v_{c 2}(i+1)=\left(1-\frac{P A}{K_{2}}\right) \cdot v_{c 2}(i) \\
& i_{c 1}(i+1)=C_{1} \cdot \frac{v_{c 1}(i+1)-v_{c 1}(i)}{P A} \\
& \mathrm{i}_{\mathrm{c} 2}(\mathrm{i}+1)=\mathrm{C}_{2} \cdot \frac{\mathrm{v}_{\mathrm{c} 2}(\mathrm{i}+1)-\mathrm{v}_{\mathrm{c} 2}(\mathrm{i})}{\mathrm{PA}} \\
& \text { elseif }\left(\left(\mathrm{v}_{\text {in }}(\mathrm{i})+\mathrm{v}_{\mathrm{c} 1}(\mathrm{i})>-\mathrm{v}_{\gamma}\right) \text { and }\left(\mathrm{v}_{\text {in }}(\mathrm{i})+\mathrm{v}_{\mathrm{c} 1}(\mathrm{i})-\mathrm{v}_{\mathrm{c} 2}(\mathrm{i}) \geq \mathrm{v}_{\gamma}\right)\right) \\
& \mathrm{K}_{3}=\mathrm{R}_{\mathrm{d}} \cdot \mathrm{C}_{2} \quad ; \quad \mathrm{K}_{4}=\frac{\mathrm{R}_{\mathrm{d} 2}}{\mathrm{R}}+1 \quad ; \quad \mathrm{K}_{5}=1-\frac{\mathrm{K}_{4} \cdot \mathrm{PA}}{\mathrm{K}_{3}} \\
& \mathrm{v}_{\mathrm{c} 2}(\mathrm{i}+1)=\frac{\mathrm{PA}}{\mathrm{K}_{3}} \cdot\left(\mathrm{v}_{\mathrm{in}}(\mathrm{i})+\mathrm{v}_{\mathrm{cl}}(\mathrm{i})-\mathrm{V}_{\gamma}\right)+\mathrm{K}_{5} \cdot \mathrm{v}_{\mathrm{c} 2}(\mathrm{i}) \\
& v_{c 1}(i+1)=-\frac{P A}{C_{1}} \cdot i_{c 2}(i)-\frac{P A}{C_{1} \times R} \cdot v_{c 2}(i)+v_{c 1}(i)
\end{aligned}
$$

$$
\begin{aligned}
& i_{c 1}(i+1)=C_{1} \cdot \frac{v_{c 1}(i+1)-v_{c 1}(i)}{P A} \\
& i_{c 2}(i+1)=C_{2} \cdot \frac{v_{c 2}(i+1)-v_{c 2}(i)}{P A}
\end{aligned}
$$

else

$\mathrm{K}_{2}=\mathrm{R} \cdot \mathrm{C}_{2}$

$\mathrm{v}_{\mathrm{c} 2}(\mathrm{i}+1)=\left(1-\frac{\mathrm{PA}}{\mathrm{K}_{2}}\right) \cdot \mathrm{v}_{\mathrm{c} 2}(\mathrm{i})$

$\mathrm{i}_{\mathrm{c} 2}(\mathrm{i}+1)=\mathrm{C}_{1} \cdot \frac{\mathrm{v}_{\mathrm{c} 2}(\mathrm{i}+1)-\mathrm{v}_{\mathrm{c} 2}(\mathrm{i})}{\mathrm{PA}}$

$\mathrm{i}_{\mathrm{cl}}(\mathrm{i}+1)=0$

$\mathrm{v}_{\mathrm{cl}}(\mathrm{i}+1)=\mathrm{v}_{\mathrm{c} 1}(\mathrm{i})$

end

end

where:

- $\mathrm{PA}$ - represents the sampling period,

- NTP - represents total number of iterations (which is defined by the user).

\subsection{Simulated results}

In order to validate the previous analysis, as well as the simulation technique, the circuit under analysis was designed in Matlab using SimPowerSytems toolbox.

Table 1 shows the prototype characteristics.

Table 1 Characteristics of the Prototype

\begin{tabular}{c|c}
\hline Components & Electrical model \\
\hline Diodes (forward biased) & $\mathrm{R}_{\mathrm{f}}=0.15 \Omega, \mathrm{V}_{\gamma}=0.86 \mathrm{~V}$ \\
\hline $\mathrm{C}_{1}$ & $\mathrm{C}=1902 \mu \mathrm{F}$ \\
\hline $\mathrm{C}_{2}$ & $\mathrm{C}=4588 \mu \mathrm{F}$ \\
\hline Primary Source & $\mathrm{Vin}=22 \mathrm{~V}(\mathrm{amplitude})$ \\
\hline DC Load $\left(\mathrm{R}_{\text {Load }}\right)$ & $\mathrm{R}=100 \Omega$ \\
\hline
\end{tabular}

Both simulation results are consistent, showing that the proposed simulation technique can be used to predict the behaviour of the voltage doubler.

\section{TESTING DESIGN FORMULAS AND ALGORITHM}

In this section it will be assessed the applicability of the formulas and the algorithm presented in section 3 . For this purpose it will be considered 4 different situations (Table 2).

Table 2 Different situations considered for assessing the applicability of the design formulas

\begin{tabular}{c|c|c}
\hline Test & Primary source & Load \\
\hline 1 & & $\mathrm{R}=1000 \Omega$ \\
\hline 2 & \multirow{2}{*}{$\begin{array}{l}V_{\text {in }}=22 \mathrm{~V} \text { (amplitude) } \\
\mathrm{f}=50 \mathrm{~Hz} \text { (frequency) }\end{array}$} & $\mathrm{R}=500 \Omega$ \\
\hline 3 & & $\mathrm{R}=250 \Omega$ \\
\hline 4 & & $\mathrm{R}=100 \Omega$ \\
\hline
\end{tabular}

In the design of the voltage doubler it will be considered two fundamental specifications: 
- The average value of the output voltage: $\left\langle v_{\text {out }}\right\rangle=$ $38 \mathrm{~V}$

- The maximum output voltage ripple: $\Delta v_{\text {out }}<1.6 \mathrm{~V}$

In the following calculus, it will be considered a diode knee voltage of $0.8 \mathrm{~V}$.

As mentioned in section 3 the design formulas (14) and (15) allow us to compute both capacitors capacitance. However, those values are oversized, and for that it was proposed the algorithm shown in section 3.1. Table 3 shows the computed values of $C_{1}$ and $C_{2}$ using the previous formulas (14-15) and the algorithm (section 3.1).

Table 3 Voltage doubler design (computed values of $\mathrm{C}_{1}$ and $\mathrm{C}_{2}$ )

\begin{tabular}{c|c|c|c|c}
\hline \multirow{2}{*}{ Test } & \multicolumn{2}{|c|}{ Formulas } & \multicolumn{2}{c}{ Algorithm } \\
\cline { 2 - 3 } & $(15)$ & $(14)$ & \multicolumn{2}{c}{} \\
\cline { 2 - 5 } & $\mathrm{C}_{1}$ & $\mathrm{C}_{2}$ & $\mathrm{C}_{1}$ & $\mathrm{C}_{2}$ \\
\hline 1 & $249 \mu \mathrm{F}$ & $530 \mu \mathrm{F}$ & $215 \mu \mathrm{F}$ & $462 \mu \mathrm{F}$ \\
\hline 2 & $498 \mu \mathrm{F}$ & $1060 \mu \mathrm{F}$ & $432 \mu \mathrm{F}$ & $928 \mu \mathrm{F}$ \\
\hline 3 & $997 \mu \mathrm{F}$ & $2120 \mu \mathrm{F}$ & $866 \mu \mathrm{F}$ & $1858 \mu \mathrm{F}$ \\
\hline 4 & $2491 \mu \mathrm{F}$ & $5300 \mu \mathrm{F}$ & $2166 \mu \mathrm{F}$ & $4650 \mu \mathrm{F}$ \\
\hline
\end{tabular}

From the analysis of the above table it is possible to conclude that the proposed algorithm (section 3.1) suggests the choice of smaller capacitors:

- Test 1 - it could be chosen the following standard capacitances: $C_{1}=220 \mu \mathrm{F}$ and $C_{2}=470$ $\mu F$.

- Test 2 - it could be chosen the following standard capacitances: $C_{1}=470 \mu \mathrm{F}$ and $C_{2}=$ $1000 \mu \mathrm{F}$.

- Test 3 - it could be chosen the following standard capacitances: $C_{1}=1000 \mu \mathrm{F}$ and $C_{2}=$ $2200 \mu \mathrm{F}$.

- Test 4 - it could be chosen the following standard capacitances: $C_{1}=2200 \mu \mathrm{F}$ and $C_{2}=$ $4700 \mu \mathrm{F}$.

Considering the standard capacitance values [10], it is possible to conclude that in the test 1,2 and 4 the proposed algorithm suggests the choice of smaller capacitors.

The following table shows that the capacitance values computed in Table 3 satisfy the original specifications.

Table 4 Output voltage ripple and mean value computed using the proposed simulation technique

\begin{tabular}{c|c|c|c|c}
\hline \multirow{2}{*}{ Test } & \multicolumn{2}{|c|}{ Formulas } & \multicolumn{2}{c}{ Algorithm } \\
\cline { 2 - 5 } & $\left\langle v_{\text {out }}\right\rangle$ & $\Delta v_{\text {out }}$ & $\left\langle v_{\text {out }}\right\rangle$ & $\Delta v_{\text {out }}$ \\
\hline 1 & $38.6 \mathrm{~V}$ & $1.3 \mathrm{~V}$ & $38.1 \mathrm{~V}$ & $1.5 \mathrm{~V}$ \\
\hline 2 & $38.6 \mathrm{~V}$ & $1.3 \mathrm{~V}$ & $38.1 \mathrm{~V}$ & $1.5 \mathrm{~V}$ \\
\hline 3 & $38.6 \mathrm{~V}$ & $1.3 \mathrm{~V}$ & $38.1 \mathrm{~V}$ & $1.5 \mathrm{~V}$ \\
\hline 4 & $38.3 \mathrm{~V}$ & $1.3 \mathrm{~V}$ & $38.1 \mathrm{~V}$ & $1.5 \mathrm{~V}$ \\
\hline
\end{tabular}

\section{EXPERIMENTAL RESULTS}

To demonstrate the applicability of the design formulas and the proposed algorithm, an experimental prototype will be considered, with the following specifications: $\left(\left\langle v_{\text {out }}\right\rangle=38 \mathrm{~V}, \Delta v_{\text {out }}<1.6 \mathrm{~V}, \mathrm{R}=100 \Omega\right.$ and $\mathrm{V}_{\text {in }}=22 \mathrm{~V}$ ). The above specifications correspond to test 4, thus, the chosen capacitors are: $C_{1}=2200 \mu \mathrm{F}$ and $C_{2}=$ $4700 \mu \mathrm{F}$.

The computed capacitance values require the use of electrolytic capacitors, which typically have a tolerance of $20 \%$ [10]. It is therefore necessary to determine the electrical characteristics of the different components.

\subsection{Electrical characteristics of the components}

Fig. 7 show the $I-V$ characteristic of the rectifiers (when forward biased).

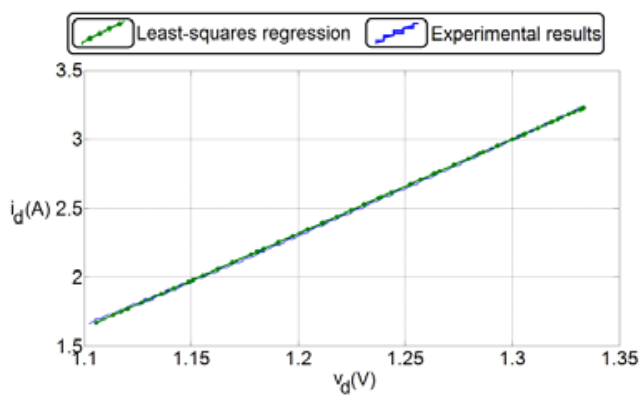

Fig. 7 Characteristic of the rectifier

Fig. 8 shows the characteristic of $C_{1}$.

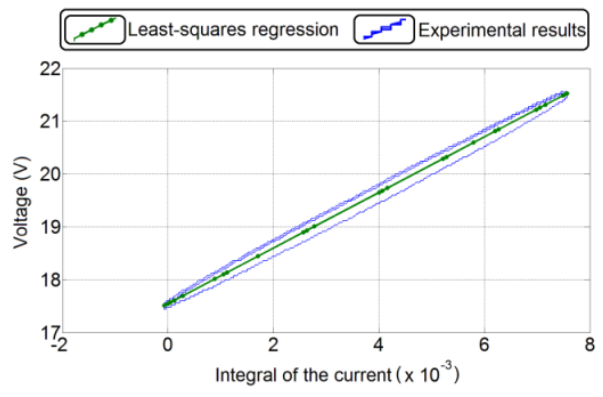

Fig. 8 Characteristic of capacitor $C_{1}$

Fig. 9 shows the characteristic of $C_{2}$.

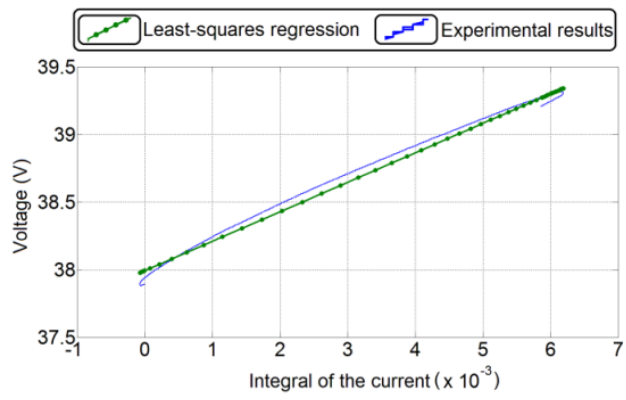

Fig. 9 Characteristic of capacitor $C_{2}$

Using least-squares regression it is possible to compute the characteristic of the rectifiers and capacitors (Table 1).

\subsection{Comparison between experimental and simulated results}

It should be also mentioned that the input voltage waveform of the voltage doubler is not exactly sinusoidal (Fig. 10a). Thus, for validation purpose, it was used an 
waveform approximately equal to the real input voltage (Fig. 10b).

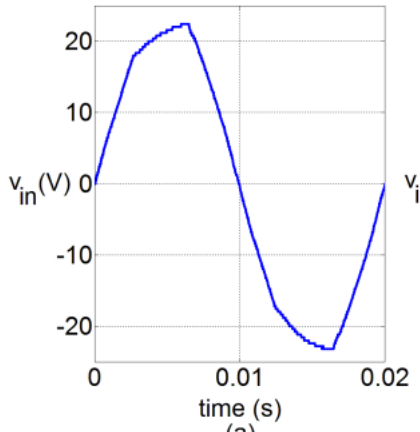

(a)

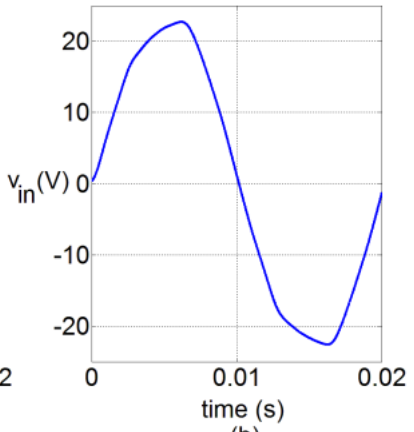

(b)
Fig. 10 Voltage waveform at the secondary of the transformer $\left(v_{\text {in }}\right)$ : (a) experimental waveform and (b) filtered experimental waveform

The experimental waveform of $v_{i n}$ has some noise, hence, it was necessary to smooth it, and for that, it was used a low pass filter (Fig. 10b).

Finally, considering the previous waveform, together with the characteristics of the components obtained experimentally, it is possible to compare the experimental results with the simulated ones.

Fig. 11, 12, 13, 14, 15 and 16 show both experimental and simulated waveforms of capacitor $C_{1}$ voltage, of capacitor $C_{1}$ current, of diode $D_{1}$ current, of diode $D_{2}$ current, of capacitor $C_{2}$ voltage and of capacitor $C_{2}$ current, respectively, during steady state regime.

The following curves are essential in the design process:

- For the capacitors: the simulated waveform of capacitor current and voltage enable the computation of current rms value and the maximum voltage.

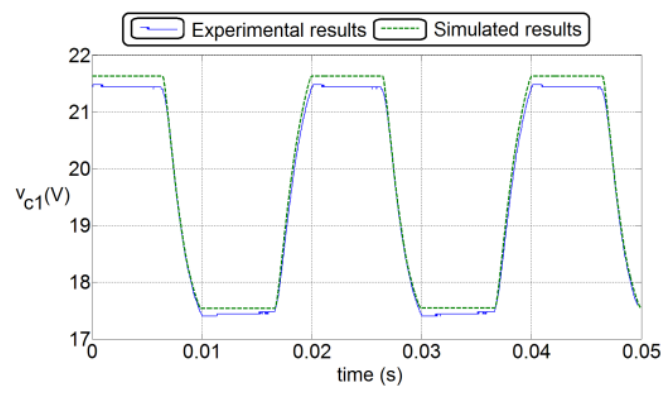

Fig. 11 Capacitor $C_{1}$ voltage waveform $\left(v_{c 1}\right)$

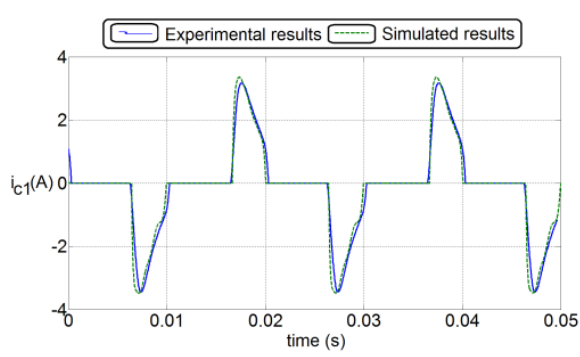

Fig. 12 Capacitor $C_{1}$ current waveform $\left(v_{c 1}\right)$
- For each rectifier: the simulated waveform of diodes current and voltage enables the computation of the maximum instantaneous reverse voltage, the peak forward surge current, the maximum forward current and the maximum forward voltage.

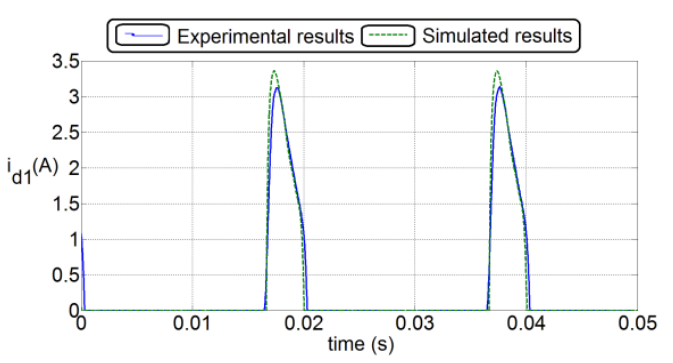

Fig. 13 Diode $D_{1}$ current waveform $\left(i_{d 1}\right)$

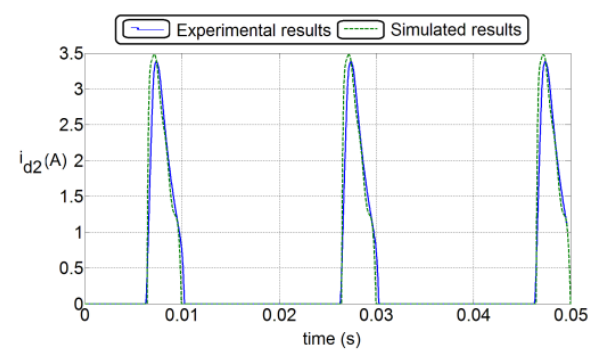

Fig. 14 Diode $D_{2}$ current waveform $\left(i_{d 2}\right)$

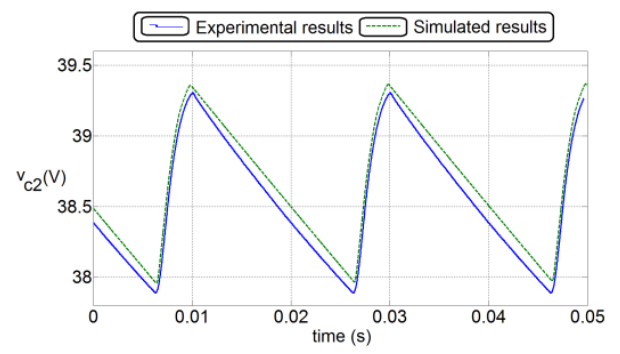

Fig. 15 Capacitor $C_{2}$ voltage waveform $\left(v_{c 2}\right)$

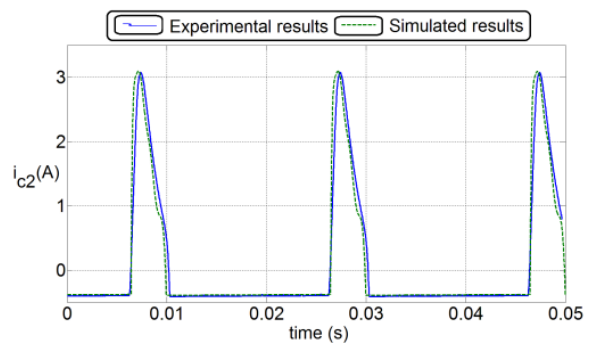

Fig. 16 Capacitor $C_{2}$ current waveform $\left(i_{c 2}\right)$

Both simulated and experimental waveforms agree, as expected.

\subsection{Results analysis}

The choice of the capacitors used in the experimental prototype had in consideration the proposed algorithm (Table 3$)$, and the initial specifications $\left(\left\langle v_{\text {out }}\right\rangle=38 \mathrm{~V}\right.$ and $\left.\Delta v_{\text {out }}=1.6 \mathrm{~V}\right)$. 
Fig. 15 shows that the ripple specification $\left(\Delta v_{\text {out }}<1.6\right.$ $V)$ was fulfilled; the ripple of the experimental prototype was equal to $1.42 \mathrm{~V}$.

However, the average voltage is slightly higher than the specified one $\left(\left\langle v_{\text {out }}\right\rangle=38 \mathrm{~V}\right)$. The average voltage of the experimental prototype was equal to $38.6 \mathrm{~V}$. This difference is due to the fact that the r.m.s. of the input voltage (Fig. 10) is higher than the r.m.s. of a pure sine wave.

\section{CONCLUSIONS}

This article discusses the design of voltage doublers for step up linear power supplies. The voltage doubler is commonly used in applications that require low currents. In such cases the capacitor selection is not an issue.

However, linear power supplies demand high current values, which make the capacitors selection complex.

In this paper some design formulas were presented that can be used in the capacitors selection. These formulas allow for the selection of oversized capacitors. To improve the price/performance ratio an algorithm that allows the selection of smaller capacitors was presented.

Furthermore, it was also presented a simple simulation technique that predicts the current and voltage waveforms in all components. The previous waveforms are essential for designing purposes.

The simulation technique, the design formulas and the algorithm were validated through experimental results.

\section{REFERENCES}

[1] AN-556 Introduction to Power Supplies, Application Report - Texas Instruments, SNVA006B, May 2004.

[2] Understand Linear Power Supply Specifications number 3137, Application Note Series - Keithley, a Tektronix Company, September 2012.

[3] AN-20-002 Application Note on Transformers, Mini-Circuits, April 2015.

[4] BECK, J.: Using Rectifiers in Voltage Multiplier Circuits, Document number: 88842, Application Note - Vishay General, July 2008.

[5] REZANEJAD, M. - SHEIKHOLESLAMI, A. ADABI, J.: Modular Switched Capacitor Voltage Multiplier Topology for Pulsed Power Supply, IEEE Transactions on Dielectrics and Electrical Insulation, Vol. 21, No. 2, pp. 635-643, Apr. 2014.

[6] REZANEJAD, M. - ADABI, J. SHEIKHOLESLAMI, A. - NAMI, A.: High-Voltage Pulse Generators Based on Capacitor-Diode Voltage Multiplier, $15^{\text {th }}$ International Power Electronics and Motion Control Conference - EPE-PEMC 2012 ECCE Europe, Novi Sad, Serbia, 4-6 September 2012, pp. LS3c 4-1- LS3c 4-6.

[7] WANG, J. - HAAN, W. - FERREIRA, J.: Detailed Derivation and Minimization of the Equivalent Parasitic Capacitances of High-Voltage Multiplier Based on the Complete Model, IEEE Transaction in Industry Applications, Vol. 51, No. 1 January/ February 2015, pp. 362-372.
[8] JEFFREY, A. - HUI-HUI, D.: Handbook of Mathematical formulas and integrals, $4 \mathrm{~d}$ ed. Oxford: Elsevier, 2008, pp. 109-148.

[9] MILLMAN, J. - GRABEL, A.: Microelectronics, 2d ed. New York: McGraw-Hill, 1987, pp. 41-78.

[10] Aluminun Electrolytic Capacitors, CAT. 8100D Nichicon.

Received June 13, 2016, accepted October 14, 2016

\section{BIOGRAPHIES}

Acácio M. R. Amaral was born in Luso, Angola, in 1974. He received the E. E. diploma, the M. S. degree and the $\mathrm{Ph}$. D degree from Coimbra's University, Portugal in 1998, 2005 and 2010, respectively. Since 1998 has been with Coimbra's Polytechnic, where is currently an Associate Professor in the Department of Informatics and Systems. His teaching interests cover Circuit Design (analogue and digital), Electronics, Digital Systems, Computer Architecture, Data Structures and Algorithms, Computer Programming in $C$ and Assembler and Signal Processing. He is the author of two books entitled Circuit and Electronic Devices Analysis (Porto, Portugal, Publindustria, 2013), (in Portuguese) and Digital Systems: Principles, Analysis and Projects (Lisboa, Portugal, Edições Sílabo, 2014), (in Portuguese), and more than 40 papers published in technical journals and conference proceedings. His research activities include fault diagnosis and design of linear and switch mode power supplies, with emphasis on the consequences of aging of electrolytic and film capacitors, as well as the development of solutions to this problem.

Antonio J. Marques Cardoso (S'89, A'95, SM'99) received the Dipl. Eng., Dr. Eng., and Habilitation degrees from the University of Coimbra, Coimbra, Portugal, in 1985, 1995 and 2008, respectively, all in Electrical Engineering. From 1985 until 2011 he was with the University of Coimbra, Coimbra, Portugal, where he was Director of the Electrical Machines Laboratory. Since 2011 he has been with the University of Beira Interior (UBI), Covilhã, Portugal, where he is Full Professor at the Department of Electromechanical Engineering and Director of CISE - Electromechatronic Systems Research Centre (http://cise.ubi.pt). He was Vice-Rector of UBI (2013-2014). His current research interests are in fault diagnosis and fault tolerance in electrical machines, power electronics and drives. He is the author of a book entitled Fault Diagnosis in Three-Phase Induction Motors (Coimbra, Portugal: Coimbra Editora, 1991), (in Portuguese) and more than 350 papers published in technical journals and conference proceedings. He serves as Guest Editor of the IEEE Transactions on Industry Applications Special Issue on Fault Diagnosis of Electric Machines, Power Electronics and Drives and Associate Editor for the IEEE Transactions on Industry Applications, IEEE Transactions on Industrial Electronics, IEEE Journal of Emerging and Selected Topics in Power Electronics, and also for the Springer International Journal of Systems Assurance Engineering and Management. 